\section{New technologies needed}

SIR - I am appalled by your article "Many catastrophes too many" (Nature 351, 171-172; 1991), and its reaffirmation of simplistic and fatally incorrect mainstream ideas on the economic development of poor nations. Modern economic theory, which is founded on the notion of continual growth, largely ignores ecological principles. Because the Earth, and all the renewable and non-renewable resources it contains, is finite, economies, and the populations they support, cannot grow indefinitely.

The unprecedented increase in world population this century has been at the expense of a staggeringly high rate of depletion (on a geological time-scale) of resources: fertile soils, timber, freshwater aquifers, mineral and fossil fuel deposits. These resources, built up over periods ranging from centuries to millions of years, are being used up in mere decades. As resources are depleted, the rate of development of all nations, industrial as well as rural, will begin first to slow and then to shrink. Economists suggest that new resources will be discovered to replace declining ones. This may be true in isolated instances (plastics replacing metals), or for a limited time (fossil fuels replacing biomass fuels). However, the present scale of loss of soil, water and fuel resources is so great that the only credible substitution would be an entire new planet.

In the cold light of ecological reality, the natural resources necessary for the industrialization of poor countries do not exist now, and will not in the foreseeable future.

In 1988, the combined global gross national product (GNP) was $\$ 15$ million million for 5,000 million people, an average per capita income of $\$ 3,000$, which supports the typical lifestyle of citizens of Portugal or Venezuela. But the average per capita income of the 1,000 million people in the most industrialized nations was $\$ 11,275$. To raise the income and lifestyle of the rest of the world to this level, the total GNP would have to increase almost fourfold, to more than $\$ 50$ million million, even if the human population does not increase further. Because of the present pyramidal ageclass demographics of the world population (more children than adults), even if a two-child per family limit were imposed in every country at this instant, the number of humans would still nearly double before levelling off. With less drastic population control measures, the projected peak in human population will be more than 15,000 million by the end of the next century.

Given that the global GNP is unlikely to increase much further (a decrease is more probable due to resource depletion), the implication is that, in the future, average per capita income will decrease to a half or even a third of the present value. Rather than the industrial development and demographic transition now expected for rural countries, a decline of all economies is more probable. If present inequities in income distribution in the world do not change, then, while the citizens of industrialized nations will merely suffer reduced circumstances, the poor are likely to fall off the edge of existence.

It is popular to deride ecological Cassandras because the Green Revolution of the 1970s temporarily matched food production and the demands of population growth, but one should not forget that in the legend the prophetess foretold correctly. Another agricultural great leap forward is not on the cards. We can no longer afford to blind ourselves to the true nature of our global predicament, which includes a changing climate due to global warming as well as a declining resource base. Appropriate new technologies based on sustainable resources, as well as population control policies, will be required for all nations, not only poor ones. It is not too late to confront reality. If we do not, then global civilization itself is at risk of disintegration.

College of Oceanography,

EVELYN B. SHERR

Oregon State University,

Oceanography Administration

Building 104,

Corvallis, Oregon 97331, USA

SIR - The leading article 'Many catastrophes too many"1 suggested approaches to disaster relief and longterm assistance for developing countries, but how would we react to devastation in the industrialized world? If we have to rebuild Los Angeles after the 'big one' hits Southern California, who would support the reconstruction of the notorious freeways and parking lots catering to photosynthetic smog produced by internal combustion engines? If we had to recreate the British power grid, would we plan generating stations requiring a Windscale/Sellafield?

Developing countries are faced with the choice: they can emulate the industrialized world and knowingly make ecological 'messes' (as suggested in the leading article) in exchange for reliance on largely imported fossil fuels and nuclear energy, or they can - ideally with North-South collaboration and assistance - follow a route towards greater self-sufficiency and sustainable development using indigenous renewable energy resources.
Your leader writer is unfortunately not alone in rejecting renewable energy systems as a phenomenon of 'Europe's dark ages' but to do so is to confound appropriate technology with primitive technology. For instance, 20 years of innovation have made windmills a viable alternative with the potential to supply 10 per cent of Britain's energy needs ${ }^{2}$. Biomass and solar energy systems are now highly efficient, capable of producing electricity for $\$ 0.04$ per kilowatt-hour ${ }^{3}$.

Through a process that emphasizes collaboration rather than simply the donation of technology, solar ovens and other wood-saving systems have been successfully integrated into rural villages in Central America ${ }^{4}$. These advances are particularly striking in the light of the small fraction of energy research funding allocated for renewables, the lack of support for efforts to develop technologies suited to the needs of developing nations ${ }^{5}$ and the range of economic impediments faced by companies developing renewable energy systems ${ }^{6}$.

Despite the immense potential of solar and windpower, the established paradigm sees renewables as having only a minor role in the economies of developed and developing countries alike. This outmoded point of view results in misinterpretation of data on modernized renewable energy technologies. Terence Price's recent Commentary ${ }^{7}$ exemplifies this line of thought: the possibility of a large-scale contribution from renewables is dismissed while rapprochement with nuclear power is advised.

A paradigm shift is in order. The obvious environmental advantages of renewable energy systems do not have to be bought at the price of economic development (although renewable energy alone will not save us from the ecological effects of over-consumption and resource exploitation). The integration of environment-friendly appropriate technology into international development assistance is not a luxury, it is a necessity.

\section{The National Children's Medical}

Research Center.

3-35-31 Taishido,

Setagaya-ku,

Tokyo, 154,

Japan

Department of Physics,

Daniel. B. Kammen

Harvard University,

Cambridge, Massachusetts 02138 ,

USA

1. Nature 351, 171-172 (1991)

2. Grubb, M. J. Energy Policy 6, 525-542 (1990)

3. Larson, E. D. \& Williams, R. H. J. Engng, Gas Turbines

Power, 112, 157-163 (1990)

4. Kammen, D. M. \& Lankford, W. F. Nature 348, 385-386 (1990).

5. Fulkerson, W. et al. Science, 246, 868-869 (1989).

6. Solomon, B. D. \& Georgianna, T. D. Energy Econ. 9, 183-192 (1987)

7. Price, T. Nature 351, 435-436 (1991).

NATURE $\cdot$ VOL $352 \cdot 29$ AUGUST 1991 